\title{
THE TRAINING OF MEDICAL STUDENTS IN THE FIELD OF PHYTOTHERAPY
}

\author{
Milev E., M. Georgieva \\ Department of Pharmacology and Toxicology, Faculty of Pharmacy \\ Medical University - Varna, Bulgaria
}

Reviewed by: assoc. prof. D. Dimitrov

\section{SUMMARY}

Now in its eigth year at the Medical University - Varna run elective course in the teaching discipline of Phytotherapy. Together with the study of medicinal plants and essential phytopreparations, during the course were monitored interests and attitudes of participants towards phytotherapy as a whole, and to individual phytotherapeutic methods and fields. At the end of each course in 2003 - 2011, a questionnaires were filled from the students-participants. Questionnaires and collected data are processed. According to them, average $\mathbf{9 4 \%}$ of participants demonstrated considerable interest in the topics, and an average of $98 \%$ of the students wish to use phytopreparations in their future practice. Despite still tentative attitude of the Bulgarian phytotherapy for clinicians, medical students demonstrate a specific interest in the area of phytotherapy and willing to update their knowledge on it in the future. Given the increasing use of phytopharmaceuticals and phyto-supplements in the world is glad, that the future doctors have a very constructive attitude towards them. We believe it would be reasonable and practical to include some phytotherapeutic topics in the regular training in pharmacology.

Key words: phytotherapy, herbalism, elective course, medicinal plants, pharmacology

Elective discipline of Phytotherapy was first introduced for the Medical University - Varna in 2002/03 academic

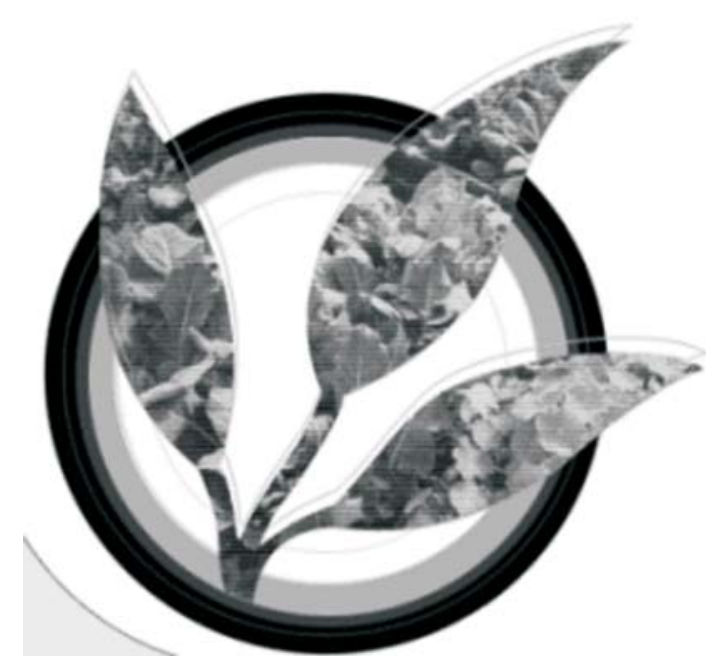

Fig. 1. Phytotherapy - Old and New

Address for correspondence:

E. Milev, Dept. of Preclinical and Clinical Pharmacology and Toxicology, Medical University of Varna "Prof. Paraskev Stoyanov" 9002 Varna, 55 Marin Drinov Street, Bulgaria

Tel. 052-677050 ext. 2654, Fax 052-650019

e-mail: e_milev_pharm@yahoo.com year. Until now 8 courses have been conducted during the summer semesters of 2003 to 2012.

A total of approx. 450 medical students have successfully completed the training. It is approximately every third student from the University. The level of interest was high about every topic, such classes are often attended by students from the Medical College - Varna, and fellow physicians.

The reason for introducing such a course was the awareness of the need of knowledge for future physicians with numer-

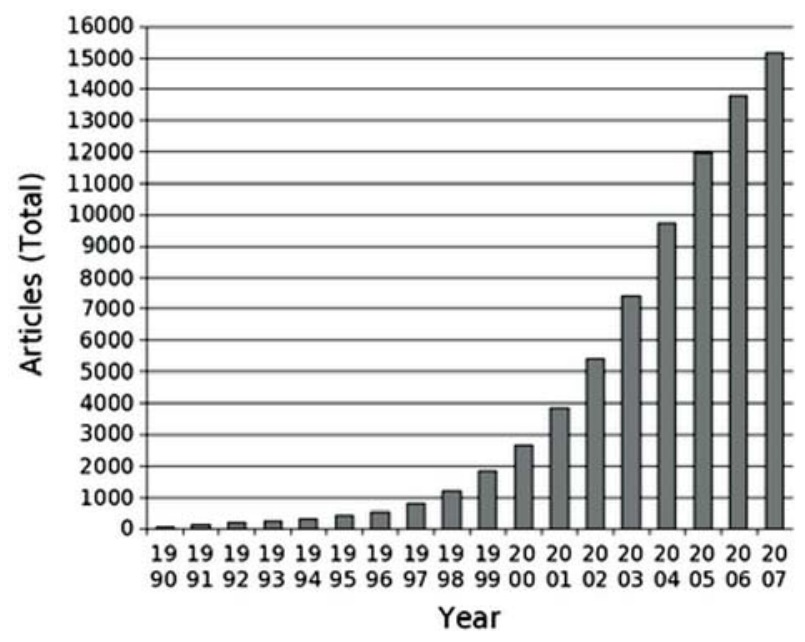

Fig. 2. Growing information in the feild of Phytotherapy 
ous and constantly increasing phytopreparations. Particularly common problem in the field of phytotherapy in Bulgaria and some other countries, is the lack of sufficient and adequate information on medicinal plants and finished phytopreparations.

The large number and variety of phytomedications often confuse the physicians and pharmacists. Studies in European Union countries shows the majority of physicians surveyed express conflicting views about phytotherapy and phytomedications. They do not know and do not use them effectively. In case reports is the use of phytopreparations in in-hospital conditions is seen, that hospital doctors totally ignored even phytotherapy of chronic diseases.

Another major reason for the introduction of this course of phytotherapy was the long tradition of herbalism and herbal treatment in Bulgaria (2). Our country is extremely rich in medicinal plants - according most data is the richest among European countries (1). Unfortunately, this natural resource is used by skilled and less skilled herbalists and folk-medicine "doctors". Recently, along the growing trend towards "green therapy" in the world, Bulgaria began to observe phenomena of the prevalence of commercial interests over medical integrity and competition among different manufacturers and/or importers of phytopreparations. Their aim is to win at any cost - i.e. to gain a big profit, regardless of efficacy and safety of these phytopreparations (4).

Future doctors (and often doctors themselves) receive information on the variety of phytopreparations from mainly promotional materials, distributed by pharmacies, company representatives, mass-media and television. This is demonstrated by surveys conducted among students from Medical University of Varna and some hospitals in Varna and from preliminary surveys carried out among doctors. It is unacceptable to inform future medical staff and doctors about the phytotherapeutic methods and preparations to be made from unreliable sources such as advertising brochures and non-professionaly written materials.

\section{Training objectives}

Main objectives of training in the course of phytotherapy were to provide enough comprehensive information for:

- Basic examples of medicinal plants, their most important botanical and phyto-biochemical characteristics, and their medical application.

- Phytomedications as a part of prophylaxis and of treatment

- Understanding the history of phytotherapy as the oldest treatment method; the main and basic schools in phytotherapy in the world

- Understanding the history and current situation of phytotherapy in Bulgaria

- Special attention was paide on a holistic approach (3) in phytotherapy:

- To heal the sick organism, not just the damaged organ

- To integrate phytotherapy with other medical areas and methods

As expected learning outcomes for students are:
- to acquire basic knowledge about medicinal plants and phytopreparations,

- and what is more important: to provoke the student's interest and encourage them to use phytotherapeutics in their future practice.

\section{Use of multimedia tools in the cource}

For the purpose of training was developed educational CD-ROM "Phytotherapy", which is updated annually. The applications of this disc are:

- To be used in the lections to display with multimedia projector images, graphics and text

- To be used independently by students at home computers or at the Library at the University.

CD-ROM "Phytotherapy" contains the following information:

- Photos and illustrations of medicinal plants

- Text information on their basic characteristics and applications

- Text material thematically oriented to individual sessions (lectures)

- Photographs of some phyto-preparations - registered in Bulgaria

- Thematically oriented materials from the Internet (as text files and images)

- Bibliographic Information for literature in Bulgarian, English and Russian languages

- A list of thematically oriented Internet - sites (over 200 available)

The noted CD-ROM was created free of charge for educational purposes only. On the disk we are not claiming any copyright. Every participant in the cource of Phytotherapy were given the opportunity to freely copy and use information from the disk. Virtually all participants identified the disc as a useful and rated especially the use of photographs (mostly herbs) during the sessions. The improvement of this educational CD-ROM is our ongoing task.

\section{Thematic plan for the phytotherapy course}

1. Introduction to phytotherapy. History and modern state. Phytotherapeutic schools and trends. Medicinal plants and plant sources. Phytotherapeutic formulations and drug forms.

2. Rewue ot the Essential Plants. Commonly used plant preparations.

3. Aromatherapy - basics, formulations and application.

4. Phytotherapy in diseases of the nervous system.

5. Phytotherapy in diseases of the cardiovascular system.

6. Phytotherapy in diseases of the digestive system. Medicinal plants and liver diseases.

7. Phytotherapy in diseases of the respiratory system, the urinary and reproductive systems.

8. Phytotherapy in diseases of the endocrine system. Phytotherapy of diseases of the musculoskeletal system and the skin.

9. Phytotherapy of infectious diseases. Medicinal plants with immunomodulatory effect. 
10. Phytotherapy in cancer. Medicinal plants and conventional cancer therapy.

\section{Content of the seminars:}

- Lectures with multimedia presentation on the topic.

- Introduction to medicinal plants - in natural form and as herbarium.

- Presenting some phytotherapeutic drugs, registered in Bulgaria.

- Open discussion on the topic.

At the beginning of the course each participant receives a complete "List of medicinal plants in Bulgaria and registered phytopreparations." This "List" serves as a plan synopsis of each lecture. All plants in it are given in Latin and 1-2 Bulgarian common names, always specifies what plant part is used. They were all out generally harmful plants, and all toxic plants (to prevent self-treatment).

Familiarize students with manufactural phytopreparations occurs after an statement that the course of Phytotherapy in no way makes corporate advertising and does not claim to fix this or that drug with such "best".

Concept in the development of this seminar plan of study was based on an understanding of the need for basic knowledge of medicinal plants and phytopreparations. Also the use of them as a full participant in the prevention and treatment of a wide range of diseases. Particular attention was paid on prevention and treatment of diseases of major social significance - as diseases of the cardiovascular, musculoskeletal and nervous systems. Hardly influenced by modern medicine conditions were considered - such as cancer, chronic joint diseases and immune deficiency. Classes on these discussion topics were met with great interest, mainly because too controversial and "sensational" information disseminated by some print and masmedia sources $(5,6,7)$.

An attempt was made to introduce as a term of "most appropriate herb, or most valuble plant" - Essential Plant $(1,3)$, leading by analogy with the concept "Essential Drug", introduced by the World Health Organization.

Under the therm "Essential Plant" we have to understand plant that meets the following minimum requirements:

\section{- High profilactic and healing efficiency}

- Wide range of applications

- Relatively low toxicity

- Easy accessibility (and reasonable price)

- Serves as a source for pharmaceutical industry

A list of about 30 plants was developed, qualifying for Essential Plants, but there is still work to his specification $(5,7,8)$.

At the end of each course was conducted survey. Participants and data from them are considered into account for shaping the next courses. Our aim was not to neglect any student opinion. At the end of course was test exam with questions, which are directed mainly towards the therapeutic use of medicinal plants.

\section{RESULTS AND CONCLUSIONS}

Conducted courses of Phytotherapy during the academic years from 2003 to 2011 convinced us that the introduction of such discipline is necessary and timely. This is illustrated by the great interest of students to those topics, the big number of their questions during the sessions (and beyond), and the large number of participants. From the distribution of participants in courses $\mathrm{I}^{\mathrm{st}}$ to $\mathrm{VI}^{\text {th }}$ total for the year at the end of the test data shows that the cource is the most visited of the III ${ }^{\text {rd }}$ and IV ${ }^{\text {th }}$ course. This fact is explainable - the teaching of pharmacology are in the same courses. It is worth noting that the actual number attended the course, but more than that, as defaulting on a final test are not reported. Especially significant is the continued presence of students from the Medical College (i.e. assistant pharmacist) for which this course could not be considered for final evaluation. In our, or any other, form of training in phytotherapy is particularly useful and relevant for students from the Medical Colleges because of the ever-increasing number and type of phytomedications in pharmacies.

The use of multimedia tools (as "CD-ROM Phytoterapy" in this case), also proved to be appropriate. Although currently available is only this product, with it's help we were able to illustrate the lectures and allow students to work independently with information on phytotherapic topics. In the future we plan to improve existing CD-ROM - make it interactive and specific database-handling. The programs in the disk will be able to search data with multifactorial approach, and with ability to adapt to the specific user.

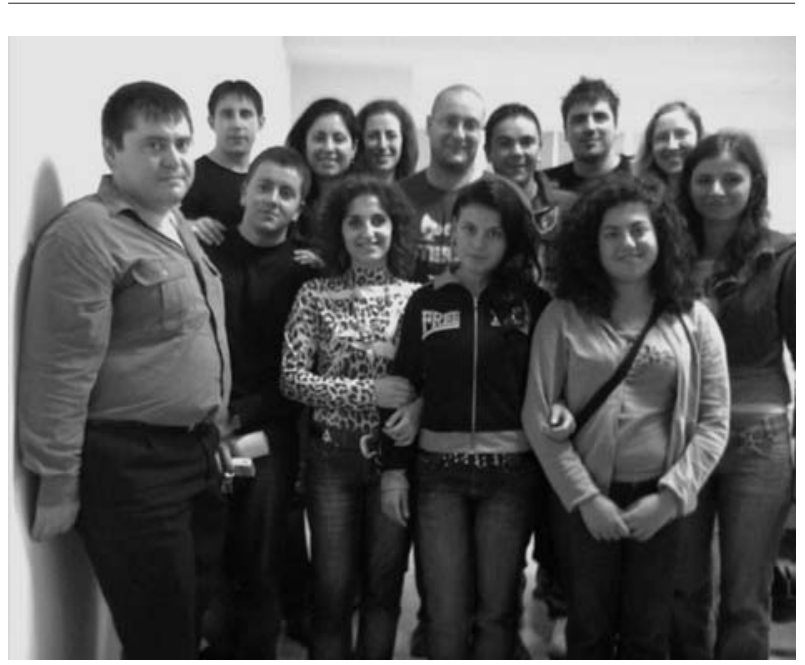

Fig. 3. Some memories from last years

Our modest eight years experience in teaching Phytotherapy would be useful to other colleagues, who would like to introduce a similar discipline. 